\title{
REZULTATI DUGOGODIŠNJEG MONITORINGA NESIDBE PLAVETNE SJENICE (Cyanistes caeruleus L.) U LISTOPADNIM ŠUMAMA SJEVEROZAPADNE HRVATSKE
}

\author{
RESULTS OF LONG-TERM MONITORING OF TIMING \\ OF LAYING IN DECIDUOUS FOREST BLUE TIT (Cyanistes \\ caeruleus L.) IN NORTHWESTERN CROATIA
}

Zdravko DOLENEC

\begin{abstract}
SAŽETAK
Evidentno, posljednjih stotinu godina došlo je do klimatskih promjena na našem planetu. Brojne promjene kod biljaka i životinja povezuju se sa klimatskim zatopljenjem, što je dokumentirano u velikom broju znanstvenih radova posljednjih dvadesetak godina. U većini slučajeva, glavni pokretač tih promjena je temperatura zraka. Najviše publiciranih članaka u vezi klimatskog zatopljenja i ptica odnosi se na fenologiju. Između ostalog, studije upućuju da je kod brojnih ptičjih vrsta došlo do ranijeg gniježđenja u posljednjih nekoliko desetljeća. Tijekom ovog istraživanja utvrđivan je trend nesidbe na temelju uzorkovanja nesenja prvog jajeta u gnijezdu lokalne populacije ptice stanarice i dupljašice plavetne sjenice (Cyanistes caeruleus) u nizinskim listopadnim šumama (prevladava hrast lužnjak Quercus robur L. i obični grab Carpinus betulus L.) u razdoblju od 1982. do 2016. godine na dijelu sjeverozapadne Hrvatske. Analiziran je i odnos između početka nesidbe i srednje proljetne temperature zraka. Podaci o polaganju jaja uzimani su iz drvenih škrinjica (umjetnih duplji) za gniježđenje ptica. Brojni ornitološki radovi temelje se na korištenju spomenutih umjetnih duplji. Sva uzorkovanja obavio je autor ovog članka. Srednja se proljetna temperature zraka značajno povećala tijekom istraživanja (od 1982. do 2016. godine). Odnos između datuma polaganja jaja i godina istraživanja bio je također statistički signifikantan. Datum početka nesidbe plavetne sjenice uznapredovao je za 11 dana u 35-godišnjem razdoblju. Dobiveni rezultati sugeriraju da je porastom proljetnih temperatura zraka tijekom dugogodišnjeg razdoblja došlo do ranijeg gniježđenja plavetne sjenice u nizinskim listopadnim šumama sjeverozapadne Hrvatske kao posljedica fenotipske plastičnosti. Očito, istraživana šumska populacija plavetne sjenice u stanju je nositi se s porastom proljetne temperature, čemu u prilog nam govori i relativna stabilnost populacije.
\end{abstract}

KLJUČNE RIJEČI: plavetna sjenica, Cyanistes caeruleus, proljetna temperatura zraka, datum nesenja, listopadne šume

UVOD

\section{INTRODUCTION}

Posljednjih stotinjak godina došlo je do globalnih i regionalnih klimatskih promjena na našem planetu (IPCC 2013), a utjecaj tih promjena, ponajprije zatopljenja, dobro je dokumentiran za živi svijet u posljednjih nekoliko desetljeća (npr. Parmesan 2006). Međutim, sve su brojniji radovi koji govore o utjecaju i u širem kontekstu, primjerice, utjecaj na turizam (npr. Pintassilgo i sur. 2016), kulturnu baštinu (npr. Bonazza i Brimblecombe 2016) itd. Klimatske 


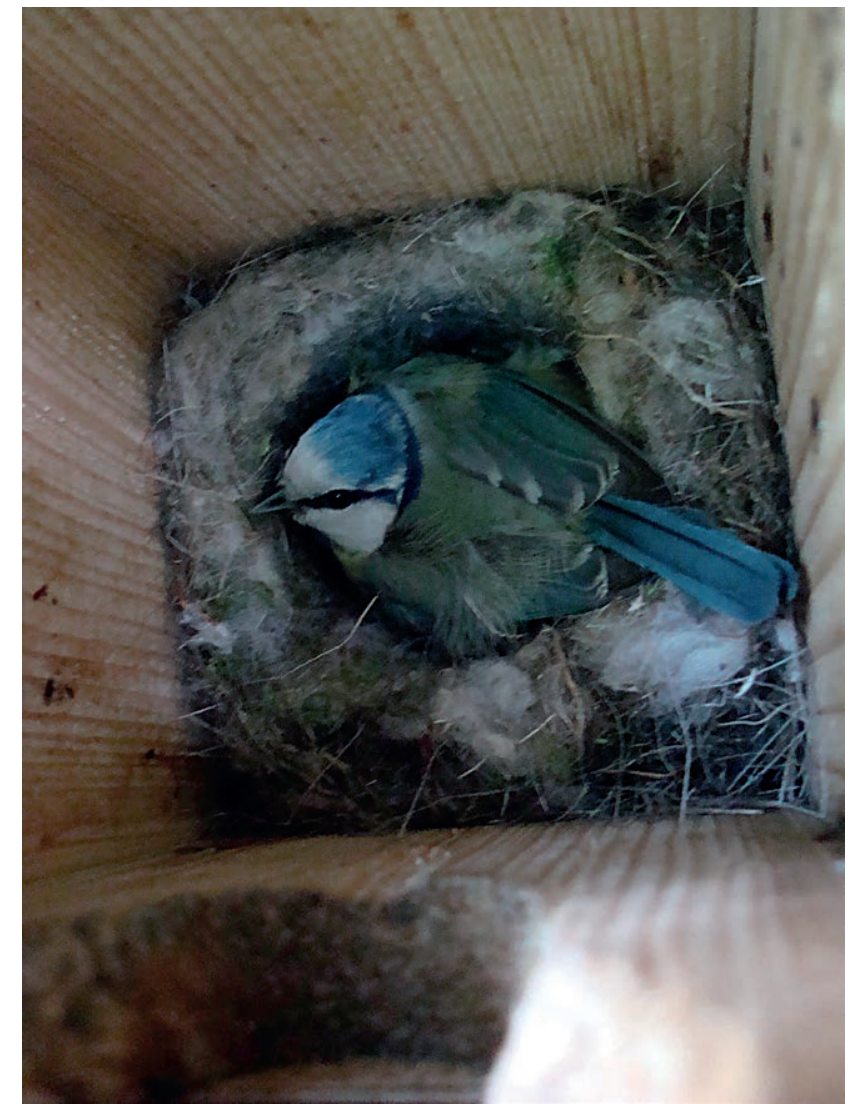

Slika 1. Gniježđenje plavetne sjenice (Cyanistes caeruleus) u škrinjici (umjetnoj duplji) (Snimio: Z. Dolenec)

Figure 1. Blue Tit (Cyanistes caeruleus) on nesting in a nest-box (artificial nest) (Photo: Z. Dolenec)

promjene utječu izravno i neizravno na mnoge sastavnice složenih šumskih ekosustava i šumarstva općenito; primjerice, na floru (npr. Mo i sur. 2017), faunu (npr. Netherer i Schopf 2010), gospodarenje šumama (npr. Sohngen i Tian 2016), tržište (Shugart i sur. 2003) itd. Reakcije čimbenika ekosustava na klimatske promjene nisu jednoznačne, a na to nas upućuju i recentna istraživanja u šumama na području Španjolske (Hidalgo-Galvez i sur. 2017). U spomenutom radu, između ostalog, prezentirani su rezultati dugogodišnjeg monitoringa cvjetanja lijeske (Corylus avellana) koji ukazuju na različita reagiranja lijeske na odvojenim lokalitetima. Prema regresijskoj analizi na lokalitetu Oviedo došlo je do signifikantnog pomaka prema ranijem cvjetanju, ali ne i na lokalitetu Tineo. Kod ptica klimatsko zatopljenje utječe na morfologiju (npr. Van Buskirk i sur. 2010), dinamiku populacija (npr. Sillett i sur. 2000), broj jaja u gnijezdu (npr. Vengerov 2017), broj potomaka (npr. Dolenec 2009a), geografsku rasprostranjenost (npr. Brommer 2004) itd. Posebice se to odnosi na njihovu fenologiju, pa je tako kod mnogih vrsta ptica došlo do promjena tijekom proljetne (npr. Croxton i sur. 2006; Dolenec i Dolenec 2010a, 2010b) i jesenske selidbe (npr. Jenni i Kéry 2003; Ożarowska i Zaniewicz 2015) te početka gniježđenja (npr. Dyrcz i Halupka 2009; Bauer i sur. 2010).
Cilj ovoga rada je utvrđivanje mogućeg trenda prema ranijem gniježđenju tijekom 35-godišnjeg monitoringa (od 1982. do 2016. godine) te istražiti eventualni utjecaj srednje proljetne temperature zraka (ožujak/travanj) na početak nesidbe plavetne sjenice na istraživanom području. Plavetna sjenica (Cyanistes caeruleus L.) prema Gillu i Wrightu (2006) pripada porodici sjenica (Paridae) i redu vrapčarki (Passeriformes), a u našim je kontinentalnim šumama među češćim pticama (npr. Kirin i sur. 2011). Ovaj je rad rezultat proširenog (nastavljenog) istraživanja praćenja trenda nesidbe plavetne sjenice na istom lokalitetu.

\section{MATERIJAL I METODE} MATERIAL AND METHODS

Istraživanje je obavljeno u listopadnim šumama uz naselje Mokrice ( $46^{\circ} 00^{\prime} \mathrm{N}, 15^{\circ} 87^{\prime} \mathrm{E}$, porječje rijeke Krapine na oko 140 m nadmorske visine, sjeverozapadna Hrvatska) u razdoblju od 1982. do 2016. godine. Šume kao dio mozaičnog krajobraza čine ostaci nekad raširene šume hrasta lužnjaka i običnog graba - Carpino betuli-Quercetum roboris /Anić 1959/ Rauš 1969 [(Vukelić i Rauš 1998)]. Listopadne šume su povoljnije za gniježđenje ove vrste u odnosu na crnogorične pa ih plavetne sjenice (kao i većina ostalih sjenica) češće naseljavaju. Razlog je zbog povoljnija ponuda hrane u razdoblju hranidbe potomaka (npr. Riddington i Gosler 1995), ali, ovisno o intenzitetu uzgajanja šuma, više povoljnih duplji za gniježđenje (npr. Newton 1998). Dio parova plavetnih sjenica gnijezdio je i u drugim staništima na području Mokrica. Ti parovi plavetne sjenice nisu analizirani budući da su prijašnji ornitološki radovi ukazali kako ekološki čimbenici različitih staništa imaju različiti utjecaj na gniježđenje ptica. Primjerice, prema Solonenu i Hildénu (2014) plavetne sjenice gnijezde ranije u suburbanim parkovima nego u ruralnim staništima, a različiti utjecaj staništa zabilježen je i u drugih vrsta ptica (npr. Wawrzyniak i sur. 2015). Tijekom ovog istraživanja uzorkovanja su obavljana uz pomoć škrinjica za gniježđenje (umjetnih duplji) veličine $12 \times 12 \times 23 \mathrm{~cm}$. U jesen 1982. godine postavljeno je 50 škrinjica, a 40 je bilo postavljeno prijašnjih godina. Ukupno je bilo oko 90 škrinjica na raspolaganju pticama tijekom razdoblja monitoringa. Dio starih i oštećenih škrinjica zamijenjivan je novima tijekom 35-godišnjeg razdoblja. Od godine do godine 16 do 41 škrinjica bilo je naseljeno istraživanom vrstom. Sagrađene su od dasaka debljine $2,5 \mathrm{~cm}$ i sve su imale pokretnu gornju dasku („krov“) kako bi se moglo pristupiti gnijezdu. Postavljane su (vješane) na debla stabala na visinu 2,5 do $4 \mathrm{~m}$ (najčešće $3 \mathrm{~m}$ ) iznad tla, a međusobno su bile udaljene ne manje od $50 \mathrm{~m}$. Škrinjice za gniježđenje su uobičajeno „pomagalo“ za razna ornitološka istraživanja (npr. Dolenec i sur. 2011a; Skwarska i sur. 2012; Kocijan i sur. 2014) budući da ih ptice dupljašice rado prihvaćaju, odnosno naseljavaju (Slika 1.). 


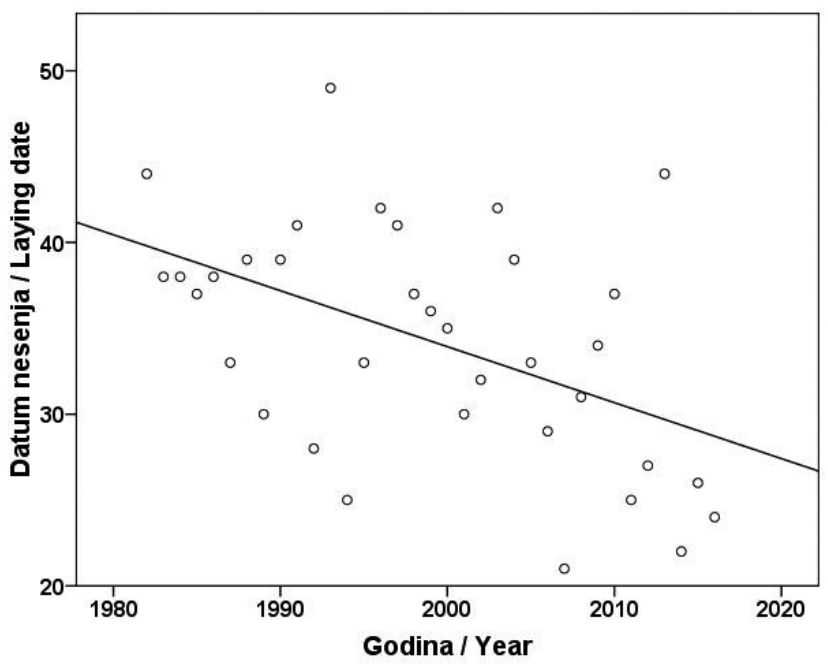

Slika 2. Dugoročni trend početka nesenja plavetne sjenice (Cyanistes caeruleus) na području sjeverozapadne Hrvatske u razdoblju od 1982. do 2016. godine ( $1=1$ ožujak)

Figure 2. Long-term trend in laying date of the Blue Tit (Cyanistes caeruleus) in northwestern Croatia, 1982-2016, (1 = 1 March)

Također, škrinjice se postavljaju i sa svrhom naseljavanje ptica dupljašica u staništa gdje nedostaje prirodnih duplji kako bi se smanjio broj štetnih kukaca. Primjerice, Estonski centar za upravljanje šumama propisuje postavljanje škrinjica (umjetnih duplii) u mlade crnogorične šume (Mänd i sur. 2005). Za početak nesidbe populacije plavetne sjenice na istraživanom području koristila se srednja vrijednost prvog snesenog jajeta dobivena iz prvih deset gnijezda u kojima su ženke počele najranije nesti (izbjegnute veće oscilacije pojedinih parova). Gnijezda su tijekom istraživanja posjećivana svakih dva do pet dana, a početak nesidbe odredio se na temelju broja jaja u gnijezdu budući da plavetne sjenice u pra-

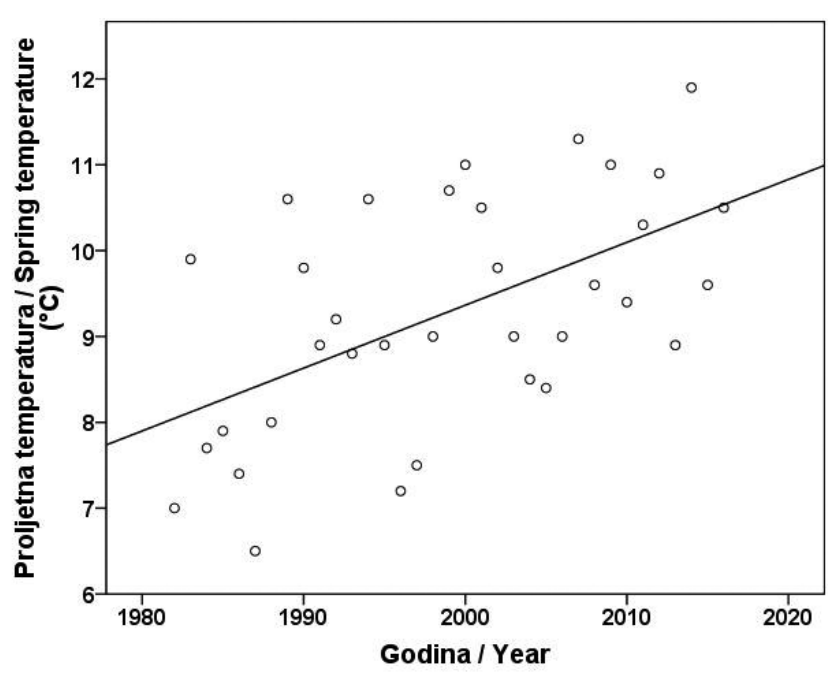

Slika 3. Korelacija između srednje proljetne (ožujak/travanj) temperature zraka i godina istraživanja (od 1982. do 2016. godine)

Figure 3. Correlation between mean spring (March/April) air temperature and year (1982-2016)

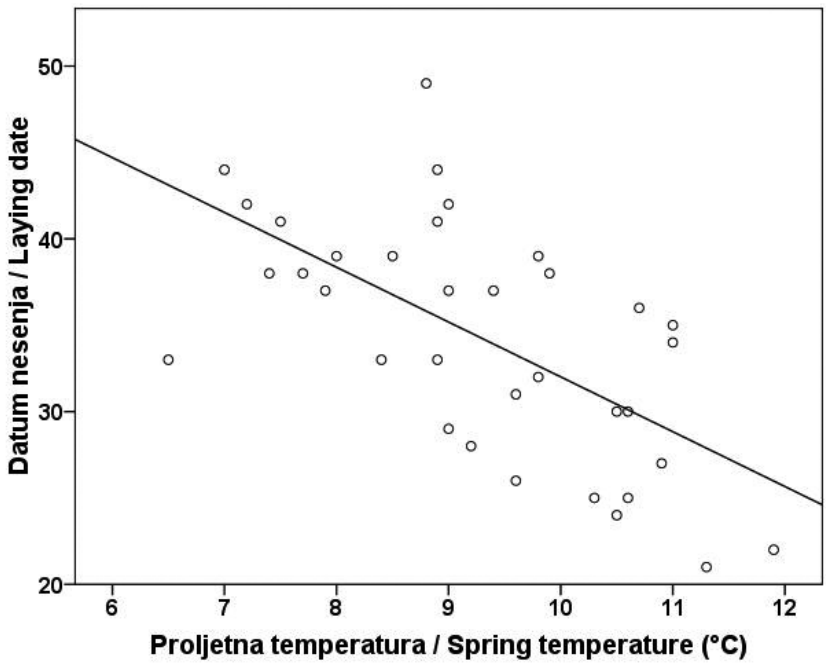

Slika 4. Korelacija između datuma početka nesenja plavetne sjenice (Cyanistes caeruleus) i srednje proljetne (ožujak/travanj) temperature zraka od 1982. do 2016. godine ( $1=1$ ožujak)

Figure 4. Correlation between laying date of the Blue Tit (Cyanistes caeruleus) and mean spring (March/April) air temperature (1982-2016) (1 = 1 March)

vilu snesu svaki dan jedno jaje. Sva uzorkovanja obavljao je autor ovog članka. Parovi koji su gnijezdili u prirodnim dupljama (ne više od 5\%) nisu analizirani.

Srednja proljetna temperatura zraka (za razdoblje od 1982. do 2016. godine) izračunata je iz podataka za mjesece ožujak i travanj (razdoblje nesidbe plavetne sjenice na istraživanom području), a korišteni su podaci s postaje Maksimir Državnog hidrometeorološkog zavoda u Zagrebu. Maksimir-Zagreb je najbliža meteorološka postaja koja je bilježila podatke od 1982. godine te je približno iste nadmorske visine kao i područje istraživanja. Udaljenost od područja fenoloških uzorkovanja plavetne sjenice iznosi 20 $\mathrm{km}$ (slične nadmorske visine). Istraživanje dugogodišnjeg utjecaja temperature zraka na fenologiju ptica nalazimo i u mnogim drugim radovima (e.g. Dunn 2004; Dolenec i Dolenec 2011b; Dolenec 2017). Statistička analiza obavljena je pomoću programskog paketa SPSS 17.0 za Windowse. Prikupljeni podaci tijekom istraživanja obrađeni su jednostavnom linearnom regresijom i Pearsonovim koeficijentom linearne korelacije (signifikantnost $\mathrm{p}<0,05$ ).

\section{REZULTATI RESULTS}

Početak nesenja plavetne sjenice varirao je od godine do godine tijekom 35-godišnjeg istraživanja. Prosječni datum nesidbe (prosjek u deset gnijezda s najranije snesenim prvim jajetom) od 1982. do 2016. godine je 3. travanj ( $\mathrm{SD}=6,86)$. Ptice su počele najranije nesti 2007. godine (21. ožujak), a najkasnije 1993. godine (18. travnja), što znači da je fenotipska plastičnost omogućila prilagođavanje početka gniježđenja istraživane populacije plavetne sjenice u rasponu od 28 
dana tijekom godina istraživanja. Statistička analiza ukazuje na signifikantni trend početka polaganja jaja, odnosno značajni odnos između nesidbe i godina istraživanja $(\mathrm{r}=-0,487$, $\mathrm{p}=0,003, \mathrm{n}=35 ; \mathrm{y}=686,03-0,326 \mathrm{x}$; Slika 2.) što znači da su plavetne sjenice gnijezdile 11 dana ranije 2016. godine u odnosu na početak monitoringa 1982. godinu. Srednja proljetna temperatura zraka (ožujak/travanj) od 1982. do 2016. godine iznosila je $9,3^{\circ} \mathrm{C}(\mathrm{SD}=1,35)$. Najniža je bila je bila 1987. godine $\left(6,5^{\circ} \mathrm{C}\right)$, a najviše 2014 . godine $\left(11,9^{\circ} \mathrm{C}\right)$. $\mathrm{U}$ istraživanom razdoblju srednja proljetna temperatura je signifikantno porasla za $2,6^{\circ} \mathrm{C}(\mathrm{r}=0,562, \mathrm{p}<0,001, \mathrm{n}=35$; y $=-140,07+0,075 x$; Slika 3.). Korelacije između proljetne temperature zraka i početka nesidbe također je signifikantna $(\mathrm{r}=-0,609, \mathrm{p}=<0,001, \mathrm{n}=35 ; \mathrm{y}=62,66-3,067 \mathrm{x}$; Slika 4. što nam govori da su plavetne sjenice toplijih proljeća pristupile ranije gniježđenju. Dobiveni podaci sugeriraju, da je ranije gniježđenje u 35-godišnjem razdoblju rezultat je dugogodišnjih proljetnih temperaturnih promjena zraka, odnosno zatopljenja.

\section{RASPRAVA I ZAKLJUČAK DISCUSSION AND CONCLUSION}

Mnogi autori naglašavaju važnost dugogodišnjeg i kontinuiranog monitoringa fenologije ptica te povezivanja dobivenih podataka uzorkovanja s aktualnim klimatskim promjenama (npr. Mcdermontt i Degroote 2016). Nužnost čim duljeg praćenja fenologije proizlazi i iz činjenice što do promjene klime ne dolazi u svim područjima istodobno, kao i zbog fluktuacija u njenom intenzitetu kroz desetljeća (npr. Watkinson i sur. 2004). Neka su fenološka istraživanja nastavljena nakon objavljenih rezultata za određeno razdoblje te su novi podaci dugogodišnjeg praćenja pokazali drukčiju sliku trenda. Primjerice, u Norveškoj (Barret 2002) nije došlo kod ptica selica do ranijeg povratka sa zimovanja u više od 20 godina istraživanja. Međutim, sljedećih desetak godina nastavljenog istraživanja pokazala su značajno raniji povratak tijekom proljetne selidbe u ukupno 30-godišnjem razdoblju (Barret 2011). Tijekom razdoblja od 1982. do 2004. godine nije bilo trenda koji bi ukazao na ranije nesenje jaja plavetne sjenice (Dolenec 2007). No, iz rezultata ovoga rada proizlazi kako se u razdoblju od 1982. do 2016. godine dogodio signifikantni pomak (11 dana) prema ranijem gniježđenju plavetne sjenice na području listopadnih šuma dijela sjeverozapadne Hrvatske, što je vjerojatno povezano s uznapredovanom fenologijom entomofaune (Visser i sur. 2006). Porast proljetne temperature i obilje hrane (prvenstveno brojnost gusjenica) najvjerojatnije je razlogom sve ranijeg gniježđenja plavetne sjenice. Promjene u fenologiji prema većini autora možemo pripisati fenotipskoj plastičnosti (npr. Charmantier i sur. 2008). Očito, istraživana populacija plavetne sjenice u šumama sjeverozapadne Hrvatske u stanju je nositi se s porastom proljetne temperature. I u drugim područjima Europe zabilježeno je značajno ranije gniježđenje plavetne sjenice. Tako je primjerice, u šumama Španjolske (Potti 2009), Belgije (Matthysen i sur. 2011) i Švedske (Källander i sur. 2017) također zabilježeno uznapredovalo gniježđenje posljednjih desetljeća. Signifikantno uznapredovalo gniježđenje nalazimo i u drugih vrsta ptica, kako u Europi, tako i u Hrvatskoj. Kod nas ranije gniježđenje zabilježeno je kod brgljeza - Sitta europaea (Dolenec 2009b), lastavica Hirundo rustica (Dolenec i sur. 2009), crnokape grmuše Sylvia atricapilla (Doleneci Dolenec 2011a), poljskog vrapca - Passer montanus (Dolenec i sur. 2011b) i mrke crvenrepke - Phoenicuros ocrurus (Dolenec i sur. 2012), ali ne i kod crnoglave sjenice - Poecile palustris (Dolenec 2006).

Budući da su već sada mnoge šume pogođene na razne načine klimatskim promjenama (Kirilenko i Sedjo 2007) te će vjerojatno, oko četiri bilijuna hektara površine Zemlje pod šumom (Food and Agriculture Organization, FAO 2005), u budućnosti biti još pod jačim utjecajem klimatskog zatopljenja. Za mnoge šumske ptičje vrste slijede razne prilagodbe kako na području fenologije tako i biologije općenito. Teško je predvidjeti kako će se u budućnosti kretati gnijezdeće populacije plavetne sjenice u šumama sjeverozapadne Hrvatske u smislu stabilnosti njihovih populacija vezano uz klimatske promjene. Prema nekim autorima znatno će više „problema“ imati ptice selice na velike udaljenosti („podsaharski migranti“), čiji je pad populacija već zabilježen (npr. Ockedon i sur. 2012) u odnosu na ptice stanarice kojima pripada plavetna sjenica. Prema Visseru i Bothu (2005) poseban problem za ptice nastaje ako dođe do nepoklapanja razdoblja gniježđenja i vrhunca ponude hrane, što može imati negativne posljedice po demografiju tih vrsta. Gnijezdeća je populacija plavetne sjenice $\mathrm{u}$ listopadnim šumama sjeverozapadne Hrvatske tijekom istraživanja bila relativno stabilna bez znatnih oscilacija brojnosti parova od godine do godine (Dolenec, neobjavljeni podaci). Posebna pozornost tijekom daljnjeg istraživanja u vezi $s$ klimatskim zatopljenjem trebat će se usmjeriti i na intraspecijsku i interspecijsku kompeticiju, moguće promjene izvora hrane, predatore, nametnike, fragmentaciju šuma, gospodarenje šumama itd., kako bi se dobila što potpunija slika stanja današnjeg i budućeg obitavanja gnijezdeće populacija plavetne sjenice u pojedinim životnim zajednicama šuma, odnosno šumskim ekosustavima.

\section{LITERATURA}

REFERENCE

- Anić, M., 1959: Šumarska fitocenologija I i II. Zagreb.

- Barrett, R. T., 2002: The phenology of spring bird migration to North Norway. Bird Study, 49: 270-277. 
- Barrett, R. T., 2011: Recent response to climate change among migrant birds in northern Norway. Ringing \& Migration, 26: 83-93.

- Bauer, Z., M. Trnka, J. Bauerová, M. Možný, P. Štěpánek, L. Bartošová, Z. Žalud, 2010: Changing climate and the phenological response of great tit and collared flycatcher populations in floodplain forest ecosystems in Central Europe. Int. J. Biometeorol., 54: 99-111.

- Bonazza, A., P. Brimblecombe, 2016: Climate and the changing appearance of buildings. In: Lefèvre, R. A., C. Sabbioni (eds): Cultural heritage from pollution to climate change. Edipuglia, Bari, pp 27-34.

- Brommer, J. E., 2004: The range margins of northern birds shift polewards. Ann. Zool. Fennici, 41: 391-397.

- Charmantier, A., R. H. McCleery, L. R. Cole, C. M. Perrins, L. E. B. Kruuk, B. C. Sheldon, 2008: Adaptive phenotypic plasticity in response to climate change in a wild bird population. Science, 320: 800-803.

- Croxton, P. J., T. H. Sparks, M. Cade, R. G. Loxton, 2006: Trends and temperature effects in the arrival of spring migrants in Portland (United Kingdom) 1959-2005. Acta Ornithol., 41: 103111.

- Dolenec, P., I. Kocijan, Z. Dolenec, 2011a: Intra-seasonal changes in reproductive strategy of a multi-brooded passerine: the tree sparrow Passer montanus. Ethology Ecology and Evolution 23: 368-374.

- Dolenec, Z., 2006: Laying date of marsh tit Parus palustris in relation to climate change. Biologia, 61: 635-637.

- Dolenec, Z., 2007: Spring Temperatures in relation to Laying Dates and Clutch Size of the Blue Tit in Croatia. Wilson J. Ornith., 119: 299-301.

- Dolenec, Z., 2009a: Impact of local air temperatures on the brood size in Starling (Sturnus vulgaris L.). Pol. J. Ecol., 57: 817-820.

- Dolenec, Z., 2009b: Effect of spring temperature on the first egglaying dates of the Nuthatch (Sitta europaea). Isr. J. Ecol. Evol., 55: 149-151.

- Dolenec, Z., 2017: Sve raniji povratak kukavice (Cuculus canorus) sa zimovanja u šume sjeverozapadne Hrvatske. Šumarski list, 141 (11-12): 467-475.

- Dolenec, Z., P. Dolenec, 2010a: Response of the Blackcap (Sylvia atricapilla L.) to temperature change. Pol. J. Ecol., 58: 605-608.

- Dolenec, Z., P. Dolenec, 2010b: Changes in spring migration of the wood pigeon (Columba palumbus) in northwestern Croatia. Turk. J. Zool., 34: 267-269

- Dolenec, Z., P. Dolenec, 2011a: Influence of the local spring warming on the breeding phenology in blackcap (Sylvia atricapilla) in Croatia. J. Environ. Biol., 35: 625-627.

- Dolenec, Z., P. Dolenec, 2011b: Spring migration characteristics of the House Martin, Delichon urbica (Aves: Hirundinidae) in Croatia: A response to climate change? Zoologia, 28: 139-141.

- Dolenec, Z., P. Dolenec, A. P. Møller, 2011b: Warmer springs, laying date and clutch size of tree sparrows Passer montanus in Croatia. Current Zoology, 57: 414-418.

- Dolenec, Z., P. Dolenec, J. Kralj, 2012: Egg-laying trends in black redstart (Phoenicurus ochruros). Current Science, 102: 970-972.

- Dolenec, Z., P. Dolenec, J. Kralj, D. Kiš-Novak, 2009: Long-term trends in timing of breeding of the Barn Swallow Hirundo rustica in Croatia. Pol. J. Ecol., 57: 611-614.

- Dunn, P. O., 2004: Breeding dates and reproductive performance. Adv. Ecol. Res., 35: 69-87.
- Dyrcz, A., L. Halupka, 2009: The response of the Great Reed Warbler Acrocephalus arundinaceus to climate change. J. Ornithol., 150: 39-44.

- Food and Agriculture Organization (FAO) 2005: Global Forest Resources Assessment 2005. Progress towards Sustainable Forest Management. Forestry Paper 147, Rome.

- Gill, F., M. Wright, 2006: Birds of the world. Princeton University Press, New Jersey.

- Hidalgo-Galvez, M. D., H. García-Mozo, J. Oteros, A. Mestre, R. Botey, C. Galán, 2018: Phenological behaviour of early spring flowering in Spain in response to recent climate change. Theor. Appl. Climatol., 132: 263-273.

- Hušek J. P., Adamík P., 2008: Long-term trends in the timing of breeding and brood size in the Red-Backed Shrike Lanius collurio in the Czech Republic, 1964-2004. J. Ornithol., 149, 97-103.

- IPCC, 2013: Working Group I Technical Support Unit. Climate Change 2013: The Physical Science Basis. Part of the Working Group I Contribution to the Fifth Assessment Report of the Intergovernmental Panel on Climate Change. Stocker TF, Qin D, Plattner GK, Tignor MMB, Allen SK, Boschung J, Nauels A, Xia Y, Bex V, Midgley PM (eds.)

- Jenni, L., M. Kéry, 2003: Timing of autumn bird migration under climate change: advances in long-distance migrants, delays in short-distance migrants. Proc. R. Soc. Lond. B, 270: 14671471.

- Källander, H., D. Hasselquist, A. Hedenström, A. Nord, H. G. Smith, J.-L. Nilsson, 2017: Variation in laying date in relation to spring temperature in three species of tits (Paridae) and pied flycatchers Ficedula hypoleuca in southernmost Sweden. J. Avian Biol., 48: 83-90.

- Kirilenko, A. P., R. A. Sedjo, 2007: Climate change impacts on forestry. Proc. Natl. Acad. Sci. USA, 104: 19697-19702.

- Kirin, T., J. Kralj, D. Ciković, Z. Dolenec, 2011: Habitat selection and similarity of the forest songbird communities in Medvednica and Žumberak - Samoborsko gorje nature parks. Šumarski list, 135 (9-10): 467-475.

- Kocijan, I., P. Dolenec, Z. Dolenec, A. Radović, 2014: Resource allocation within the replacement clutch: do female European starling (Sturnus vulgaris) adjust their reproductive strategy after a full clutch loss? Current Science, 107: 1597-1601.

- Matthysen, E., F. Adriaensen, A. A. Dhondt, 2011: Multiple responses to increasing spring temperatures in the breeding cycle of blue and great tits (Cyanistes caeruleus, Parus major) Global Change Biol., 17: 1-16.

- Mcdermontt, M. E., L. W. Degroote, 2016: Long-term climate impacts on breeding bird phenology in Pennsylvania, USA. Global Change Biol., 22: 3304-3319.

- Mo, F., J. Zhang, J. Wang, Z-G. Cheng, G-J. Sun, H-X. Ren, X-Z. Zhao, W. K. Cheruiyot, L. Kavagi, J-Y. Wang, Y-C. Xiong, 2017: Phenological evidence from China to address rapid shifts in global flowering times with recent climate change. Agricul. and Forest Meteorol., 246: 22-30.

- Mänd R., V. Tilgar, A. Lõhmus, A. Levitas, 2005: Providing nest boxes for hole-nesting birds - Does habitat matter? Biodivers. Conserv., 14: 1823-1840.

- Netherer, S., A. Schopf, 2010: Potential effects of climate change on insect herbivores in European forests - General aspects and the pine processionary moth as specific example. For. Ecol. Manage., 259: 831-838.

- Newton, I., 1998: Population limitation in birds. Academic Press, London. 
- Ockedon, N., C. M. Hewson, A. Johnston, P. W. Atkinson, 2012: Decline in British-breeding populations of Afro-Palearctic migrant birds are linked to bioclimatic wintering zone in Africa, possibly via constraints on arrival time advancement. Bird Study, 59: 111-125.

- Ożarowska, A., G. Zaniewicz, 2015: Temporal trends in the timing of autumn migration of short- and long-distance migrating Blackcaps (Sylvia atricapilla). Ornis Fennica, 92: 144152.

- Parmesan, C. 2006: Ecological and evolutionary responses to recent climate change. Annu. Rev. Ecol. Evol. Syst., 37: 637-669.

- Pintassilgo, P., J. Rosselló, M. Santana-Gallego, E. Valle, 2016: The economic dimension of climate change impacts on tourism. Tourism Economics, 22: 685-698.

- Potti, J., 2009: Advanced breeding dates in relation to recent climate warming in a Mediterranean montane population of Blue Tits Cyanistes caeruleus. J. Ornithol., 150: 893-901.

- Riddington, R., A. G. Gosler, 1995: Differences in reproductive success and parental qualities between habitats in the Great Tit Parus major. Ibis 137: 371-378.

- Shugart, H, R. Sedjo, B. Sohngen, 2003: Forest and global climate change: Potential impacts on U.S. forest resources. Pew Center on Global Climate Change, Washington.

- Sillett, T. S., R. T. Holmes, T. W. Sherry, 2000: Impacts of a global climate cycle on population dynamics of a migratory songbird. Science, 288: 2040-2042.

- Skwarska, J., A. Kaliński, J. Wawrzyniak, M. Markowski, W. Mikus, M. Bańbura, M. Glądalski, P. Zieliński, J. Bańbura, 2012: Long-term variation in laying date and clutch size of Pied Flycatchers Ficedula hypoleuca in central Poland. Pol. J. Ecol., 60: 187-192.
- Sohngen, B., X. Tian, 2016: Global climate change impacts on forests and markets. Forest Policy and Economics, 72: 18-26.

- Solonen, T., M. Hildén, 2014: Breeding phenology in Great and Blue Tits (Parus spp.): are urban populations more resistant to climate change than rural ones? Ornis Fennica, 91: 209-219.

- Van Buskirk, J., R. S. Mulvihill, R. C. Leberman, 2010: Declining body sizes in North American birds associated with climate change. Oikos, 119: 1047-1055.

- Vengerov, P. D., 2017: Effect of Rise in Spring Air Temperature on the Arrival Dates and Reproductive Success of the Song Thrush, Turdus philomelos (C. L. Brehm, 1831) in the ForestSteppe of the Russian Plain. Russ. J. Ecol., 48: 178-184.

- Visser, M. E., C. Both, 2005: Shift in phenology due to global climate change: the need for a yardstick. Proc. R. Soc. Lond. B, 272: 2561-2569.

- Visser, M. E., L. J. M. Holleamn, P. Gienapp, 2006: Shifts in caterpillar biomass phenology due to climate change and its impact on the breeding biology of an insectivorous bird. Oecologia, 147: 164-172.

- Vukelić, J., Đ. Rauš, 1998: Šumarska fitocenologija i šumske zajednice u Hrvatskoj, Šumarski fakultet Sveučilišta u Zagrebu, 310 str.

- Watkinson, A. R., J. A. Goll, M. Hulme, 2004: Flyng in the face of climate change: a review of climate change, past, present and future. Ibis, 146 (Suppl. 1): 4-10.

- Wawrzyniak, J., A. Kaliński, M. Glądalski, M. Bańbura, M. Markowski, J. Skwarska, P. Zieliński, I. Cyżewska, J. Bańbura, 2015: Long-term variation in laying date and clutch size of the great tit Parus major in central Poland: a comparison between urban parkland and deciduous forest. Ardeola, 62: 311-322.

\section{SUMIMARY}

In the last 100 years, climate warming (climate change) phenomenon has been present on our planet. Numerous biological features of organisms have been linked to climate change and many papers in the last few decades have illustrated changes in natural biological systems. In most cases, these responses are associated with changes in air temperature. In birds, most of the published works are looking at phenology. Such studies suggest that the laying date is advancing. In this study, I examined longterm changes in the date of clutch initiation in sedentary local hole-nesting population of the Blue Tit (Cyanistes caeruleus) in deciduous forest (dominated Pediculate Oak Quercus robur L. and Common Hornbeam Carpinus betulus L.) from 1980 to 2016 (northwestern Croatia). Also, I examined relationship between timing of breeding and mean spring air temperature. All the records used in this work, as well as numerous ornithological papers around the world have been based on the use of nest-boxes by birds. The boxes were placed on the trees, at 2.5 to $4 \mathrm{~m}$ above ground and all nest-boxes had a sliding top in order to monitor nest. All observations were recorded by the author. Spring mean local air temperatures during research period have significant increase. Relationship between laying date and year was also significant. The breeding date in researched species has advanced by 11 days in study period. According to my results, sedentary local population of the Blue Tit in northwestern Croatia was able to respond to spring warming changes during 37 -year period.

KEY WORDS: Blue Tit, Cyanistes caeruleus, spring air temperature, laying date, deciduous forest 